\title{
Small Intestinal Monomorphic Epitheliotropic T-Cell Lymphoma
}

National Cancer Institute

\section{Source}

National Cancer Institute. Small Intestinal Monomorphic Epitheliotropic T-Cell

Lymphoma. NCI Thesaurus. Code C150504.

A monomorphic epitheliotropic intestinal T-cell lymphoma arising from the small intestine. It is characterized by the presence of a monomorphic cellular infiltrate of small to medium-sized T-lymphocytes that are cytotoxic and express CD56. It is not associated with celiac disease. 